\title{
Curiosity and other attitudes towards sex robots: Results of an online survey
}

\author{
Marianne Brandon ${ }^{\mathrm{a}, *}$, Nadezhda Shlykova ${ }^{\mathrm{b}}$ and Abraham Morgentaler ${ }^{\mathrm{c}, * *}$ \\ a Private Practice, Boston MA, USA \\ ${ }^{\mathrm{b}}$ Men's Health Boston, Boston MA, USA \\ ${ }^{\mathrm{c}}$ Men's Health Boston, USA; Harvard Medical School, USA
}

\begin{abstract}
As artificial intelligence and technology advance, mobile robots capable of human intimacy are an inevitable consequence of this progress. Such a profound shift in sexual technology will herald both advantages and disadvantages for human intimate relationships, yet a paucity of research exists on the study of human-robot sexual relationships. We believe a greater understanding of attitudes toward sex robots will be of value as this emerging technology progresses from its currently incipient stage. We conducted an online survey exploring potential gender differences in attitudes and opinions about sex robots. Survey responses were analyzed by gender, age, relationship status, relationship satisfaction and sexual satisfaction. Results confirm our hypothesis, that men report more positive reactions to sex with robots than women. Indeed, on no question did women report more enthusiasm or optimism about the arrival of sex robots than did men. This conclusion begs the question, what will sex robots mean to the future of gender relations, and in particular, sexual relationships? Engaging one another in a dialogue about the increasing impact technology will have on human intimacy can only strengthen our efforts to mold its effect into a primarily positive one. In addition, it is our expectation that dialogue about these gender differences can assist psychologists, sex therapists, anthropologists, roboticists and couples in navigating technological advancements as they increasingly impact human intimacy. Indeed, this dialogue may be increasingly urgent as the sudden and severe impact of COVID-19 raises increasing safety concerns for human/human sexual relationships.
\end{abstract}

\section{INTRODUCTION}

Ours is a fascinating moment in history. Advances within the fields of technology and artificial intelligence interface with nearly every aspect of human existence. Controversy abounds with regards to the potential capabilities of artificial intelligence, the risks they pose to humans, and the timeliness with which these capabilities may be realized. These debates are compounded by exaggerated expectations (Goertzel, 2015; Baum et al., 2011) and significant variation in professional opinion (Baum et al., 2017; Sotala and Yampolskiy, 2015). Nonetheless, many experts in artificial intelligence predict that within 20-55 years, high level machine intelligence will reach human ability (Muller and Bostrom, 2016). Currently, mobile intelligent machines display complex ambulatory abilities such as climbing ladders and running over rocks. As artificial intelligence and technology advance, mobile robots capable of human intimacy are an inevitable consequence of this progress. Scholars are calling for increased attention and research on what will likely become dramatic shifts in human sexual expression (Doring and Poschl, 2018; Scheutz and Arnold, 2016).

Sex robots will likely benefit humans in a variety of ways, including providing emotionally, physically, and intellectually disabled persons with opportunities for intimacy, enhancing sex therapy and sex education techniques, providing partners to those who are geographically isolated, and creating

\footnotetext{
*Corresponding author. E-mail: drbrandon@ comcast.net; Tel.: 1(410) 280-3888.

** Men's Health Boston, Boston MA, USA; Beth Israel Deaconess Medical Center; Harvard Medical School, USA 2589-9953 @ 2022 - The authors. Published by IOS Press. This is an Open Access article distributed under the terms of the Creative Commons Attribution-NonCommercial License (CC BY-NC 4.0).
} 
novel sexual experiences for individuals and couples. Yet the potential negative consequences of sex robots are disturbing. Possible disruption in human intimate relationships by the availability of sex with robots is a concern voiced by many (Richardson, 2019). Challenges appear numerous, and include the objectification of women, the potential for disruption in human-human sexual relationships, and the availability of humanoid sex partners that model a lack of personal need or agency. As an alternative sex partner, sex robots create new avenues of concern for jealous partners (Szczuka and Kramer, 2018). It is suggested that even less humanoid sexual technologies may shape the way we give meanings and values to love and sex in general (Liberati, 2020), and that the availability of sex robots seems to possess the potential to modify cultural morals (Bergen, 2020). Researchers have explored the possibility that men could find sex robots more attractive partners than humans (Szczuka \& Kramer, 2017a; 2017b), and that humans can fall in love with their sex robot (Viik, 2020).

The public's perceptions and attitudes toward sex robots reveals that their lack of exposure to robots may support fear of their potential and hesitations about intimacy with robots. Indeed, watching robots was shown in one study to be more pleasurable than the more intimate act of touching them (Edirisinghe et al., 2018). The degree to which humans are currently self-identifying as different from robots may also contribute to a hesitancy toward intimacy with machines (Edirisinghe and Cheok, 2017). A negative attitude towards robots more generally, and an anthropomorphic tendency were found to impact the willingness to purchase a sex robot (Szczuka and Kramer, 2017a).

Few studies have addressed gender differences in opinions about sex robots (Richards et al., 2017; Scheutz and Arnold, 2016, 2018), at least among English-speaking journals. This may be due in part because the existence of gender differences remains a controversial issue within the social sciences (Geher and Gambacorta, 2010), though less so within the biological sciences (de Vries \& Forger, 2015). Even an oft-cited meta-analysis supporting gender similarities in sexual attitudes and behaviors (Peterson and Hyde, 2010) found that males reported more sexual activity than females in 13 of the 14 sexual behaviors assessed, and more permissive attitudes than women in most variables measured. While only $17 \%$ of their large sample were adults ages 30-55, these authors nonetheless concluded that most gender differences in sexual attitudes and behaviors are small. However, gender differences in sexual attitudes and behavior may be expressed more obviously in the context of intimate relationships than on questionnaires (Brandon and Morgentaler, 2016). Further, gender differences may be increasingly relevant to society as new developments in gender relations such as \#metoo (Kunst et al., 2019), decreases in sexual frequency (Ueda et al., 2020; Burghardt et al., 2020) and COVID-19 (Ibarra et al., 2020) yield new challenges for intimate relationships.

It remains unclear how gender differences will influence the reception of sex robots and their impact on human intimacy. Much of the existing research focuses on the myriad legal and ethical challenges created by intimacy with technology (Danaher and McArthur, 2017). Research that does explore gender differences in attitudes toward sex robots has focused on the potential capabilities and uses of sex robots, as well as their possible advantages and disadvantages for humankind (Scheutz and Arnold, 2018, 2016). Men and women seem to demonstrate largely divergent opinions about sex robots, and these differences appear immune to cohort effects. For example, men were consistently and significantly more apt to consider multiple uses of sex robots as "appropriate" (Scheutz and Arnold, 2016). While approximately $2 / 3$ of men felt "in favor" of using a sex robot personally, $2 / 3$ of women were "against" such personal use. These authors sought to clarify these findings in a second survey (Scheutz and Arnold, 2018).

Once sex robots become more widely available, controversies regarding sex robots that are currently being explored on a societal level will inevitably be experienced within the context of intimate relationships. Sex therapists, psychotherapists and sexual medicine specialists will eventually need to 
assist couples in negotiating these unavoidable challenges. While the small number of published surveys to date have addressed general attitudes toward sex robots, this study aims to extend the existing literature by exploring questions that will have relevance to professionals assisting individuals and couples. In this study we explore issues such as gender differences, perceiving sex with a robot to be a form of cheating, and willingness to sexually engage a robot differently than a human partner, as well as the ways relationships status, degree of sexual satisfaction in current relationship, and emotional connection with current sexual partner may impact attitudes toward sex robots.

\section{METHODS}

\subsection{Survey}

An 11-question online survey (Table 1) was developed to investigate perceptions and attitudes regarding sex robots. Questions were chosen with the aim of serving as a brief preliminary investigation of potentially pertinent considerations. Participants were informed that they would be taking a confidential survey titled "The Future of Sex." The survey requested information regarding gender, demographics, and current relationship status and satisfaction. Additional questions queried attitudes towards sex robots using a 5-point Likert scale. Responses were analyzed by gender, age, relationship status, relationship satisfaction and sexual satisfaction. Surveys were obtained May 21, 2019 through October 13, 2019 via SurveyMonkey. The survey required less than 5 minutes to complete. SurveyMonkey recruits participants via email who have previously offered to donate time in exchange for SurveyMonkey donating $\$ .50$ per survey to a charity of their choice. In addition, participants were offered a nominal fee of $\$ .25$ for completing the survey. SurveyMonkey gathers general data on subjects, such as their geographic region and income, when they sign up as survey respondents.

\subsection{Statistical analysis}

Descriptive analysis was performed on the study population. Responses between groups were compared using Chi square analysis. For several analyses, positive (eg, "likely and "very likely") and negative responses ("unlikely," and "very unlikely") were grouped.

\subsection{Survey respondents}

There were 313 survey respondents, consisting of 163 men, 146 women, and 4 individuals who identified as non-binary. Because of the limited number of non-binary subjects, those 4 were excluded from analysis, leaving a study population of 309 , with $52.8 \%$ male and $47.2 \%$ female. All respondents were from the United States, with broad geographical distribution as follows: $22.1 \%$ in the South Atlantic region, 17.8\% Pacific, 15.2\% East North Central, 13.4\% Middle Atlantic, 8.9\% West South Central, 7.4\% East South Central, 6.0\% West North Central, 5.2\% Mountain, and 4.3\% from New England. Income ranged from less than $\$ 10,000$ to greater than $\$ 200,000$, with a mode of $\$ 50,000-\$ 74,999$.

Respondents self-identified over the following age ranges: 18-24 years, 25-34 years, 35-44 years, 45-54 years, 55-64 years, and 65 years or older. The percentage of respondents in each age bracket is shown in Table 2. There were roughly equal numbers of individuals 44 years and younger $(49.2 \%)$ and 45 years and older $(50.8 \%)$, with the largest group being $45-54$ years. 
Table 1

"Future of Sex" survey with a 5-point likert scale

\begin{tabular}{|c|c|c|c|c|c|c|}
\hline What is your gender? & Male & Female & Transgender & Queer & Other & \\
\hline What is your age? & $18-24$ & $25-34$ & $35-44$ & $45-54$ & $55-64$ & $65+$ \\
\hline What is your relationship status? & Single & $\begin{array}{l}\text { Married/or } \\
\text { in a } \\
\text { long-term } \\
\text { committed } \\
\text { relationship }\end{array}$ & Divorced & Widowed & & \\
\hline $\begin{array}{l}\text { If you are currently in a relationship, how } \\
\text { emotionally connected do you feel with } \\
\text { your partner? }\end{array}$ & $\begin{array}{l}\text { A great } \\
\text { deal }\end{array}$ & A lot & $\begin{array}{c}\text { Moderate } \\
\text { amount }\end{array}$ & A little & Not at all & \\
\hline $\begin{array}{l}\text { How satisfied are you with your sex life } \\
\text { currently? }\end{array}$ & $\begin{array}{c}\text { Very } \\
\text { satisfied }\end{array}$ & Satisfied & $\begin{array}{l}\text { Neither } \\
\text { satisfied or } \\
\text { dissatisfied }\end{array}$ & Dissatisfied & $\begin{array}{c}\text { Very } \\
\text { dissatisfied }\end{array}$ & \\
\hline $\begin{array}{l}\text { How curious are you to have sex with a } \\
\text { robot? }\end{array}$ & $\begin{array}{l}\text { A great } \\
\text { deal }\end{array}$ & A lot & $\begin{array}{c}\text { Moderate } \\
\text { amount }\end{array}$ & A little & Not at all & \\
\hline Do you consider sex with a robot cheating? & Yes & No & & & & \\
\hline $\begin{array}{l}\text { Can you imagine having feelings for a } \\
\text { robot, if that robot acts loving towards you } \\
\text { and appears to like being around you? }\end{array}$ & $\begin{array}{l}\text { Very } \\
\text { likely }\end{array}$ & Likely & $\begin{array}{l}\text { Neither } \\
\text { likely or } \\
\text { unlikely }\end{array}$ & Unlikely & $\begin{array}{l}\text { Very } \\
\text { unlikely }\end{array}$ & \\
\hline $\begin{array}{l}\text { Could you be more comfortable doing } \\
\text { certain sex acts with a robot than with your } \\
\text { partner? }\end{array}$ & $\begin{array}{l}\text { Very } \\
\text { likely }\end{array}$ & Likely & $\begin{array}{l}\text { Neither } \\
\text { likely or } \\
\text { unlikely }\end{array}$ & Unlikely & $\begin{array}{l}\text { Very } \\
\text { unlikely }\end{array}$ & \\
\hline $\begin{array}{l}\text { If you found out that your partner had sex } \\
\text { with a robot, how would you feel? }\end{array}$ & $\begin{array}{l}\text { Strongly } \\
\text { approve }\end{array}$ & Approve & $\begin{array}{l}\text { Neither } \\
\text { approve or } \\
\text { disapprove }\end{array}$ & Disapprove & $\begin{array}{c}\text { Strongly } \\
\text { disapprove }\end{array}$ & \\
\hline $\begin{array}{l}\text { Do you look forward to a time when sex } \\
\text { with robots is easily available? }\end{array}$ & $\begin{array}{l}\text { A great } \\
\text { deal }\end{array}$ & A lot & $\begin{array}{l}\text { Moderate } \\
\text { amount }\end{array}$ & A little & Not at all & \\
\hline
\end{tabular}

Table 2

Demographic characteristics of the sample, age $(n=309)$

\begin{tabular}{lcr}
\hline & Frequency & Percent \\
\hline $18-24$ & 32 & 10.4 \\
$25-34$ & 63 & 20.4 \\
$35-44$ & 57 & 18.4 \\
$45-54$ & 96 & 31.1 \\
$55-64$ & 46 & 14.9 \\
$65+$ & 15 & 4.9 \\
Total & 309 & 100.0 \\
\hline
\end{tabular}

Relationship status is shown in Table 3. Nearly three-quarters of respondents were either married or in long-term committed relationships. For those in a committed relationship, when asked how emotionally connected they felt to their partner, 58.5\% responded "a great deal", $20.6 \%$ responded "a moderate amount," and 20.9\% responded "a little." Among all respondents, $49.8 \%$ indicated they were satisfied with their sex life, $22.7 \%$ neither satisfied nor dissatisfied, and $27.5 \%$ were dissatisfied. 
Table 3

Demographic characteristics of the sample, relationship status $(n=309)$

\begin{tabular}{lrr}
\hline & Frequency & Percent \\
\hline Single & 59 & 19.1 \\
Married, or in a long-term committed relationship & 230 & 74.4 \\
Divorced & 16 & 5.2 \\
Widowed & 4 & 1.3 \\
Total & 309 & 100.0 \\
\hline
\end{tabular}

\section{RESULTS}

\subsection{Attitudes toward sex robots}

\subsubsection{Entire study population}

Responses to questions regarding attitudes toward sex robots for the entire study population are presented in Table 4. In response to the question "How curious are you to have sex with a robot?" $61.5 \%$ responded "none at all", and only 12\% indicated "a lot" or "a great deal". A similar result was obtained for the question "Do you look forward to a time when sex with robots is easily available?" in that $62.8 \%$ responded "not at all", and $12.0 \%$ responded "a great deal" or "a lot". In response to the question "Do you consider sex with a robot to be a form of cheating?" the population was split with $47.1 \%$ responding "yes", and 52.1\% responding "no".

Table 4

Responses regarding attitudes towards sex robots, general population $(n=313)$

\begin{tabular}{lcc}
\hline & Not at all & A lot/great deal \\
\hline How curious are you to have sex with a robot? & $61.5 \%$ & $12 \%$ \\
Do you look forward to a time when sex with robots is easily available? & $62.8 \%$ & $12 \%$ \\
Do you consider sex with a robot to be a form of cheating? & Yes & No \\
& $47.1 \%$ & $52.1 \%$ \\
\hline
\end{tabular}

\subsubsection{Influence of gender}

We hypothesized there would be gender differences in attitudes toward sex robots. This was true for several questions but not all, with men generally having a more positive response than women. Results by gender are shown in Fig. 1. For example, in response to the question, "How curious are you to have sex with a robot?" $74.0 \%$ of women responded "not at all" compared with $50.3 \%$ of men $(p<0.001)$.

For the question "Do you look forward to a time when sex with robots is easily available?" $24.7 \%$ of women expressed some interest, and $75.3 \%$ none. In contrast, $48.5 \%$ of men expressed interest, including $18.4 \%$ a great deal; $51.5 \%$ responded none at all $(p<0.001)$.

Men were twice as likely as women to be more comfortable engaging in certain sex acts with a robot than with a human partner (37\% vs $17 \%$ respectively, $p<0.001$ ).

Interestingly, we saw relatively small differences in responses between genders to the question "Do you consider sex with a robot to be a form of cheating?" Women's responses were: $52.7 \%$ yes and $47.3 \%$ no. In contrast, $42.0 \%$ of men responded yes and $58.0 \%$ responded no, $(p=0.05)$. 


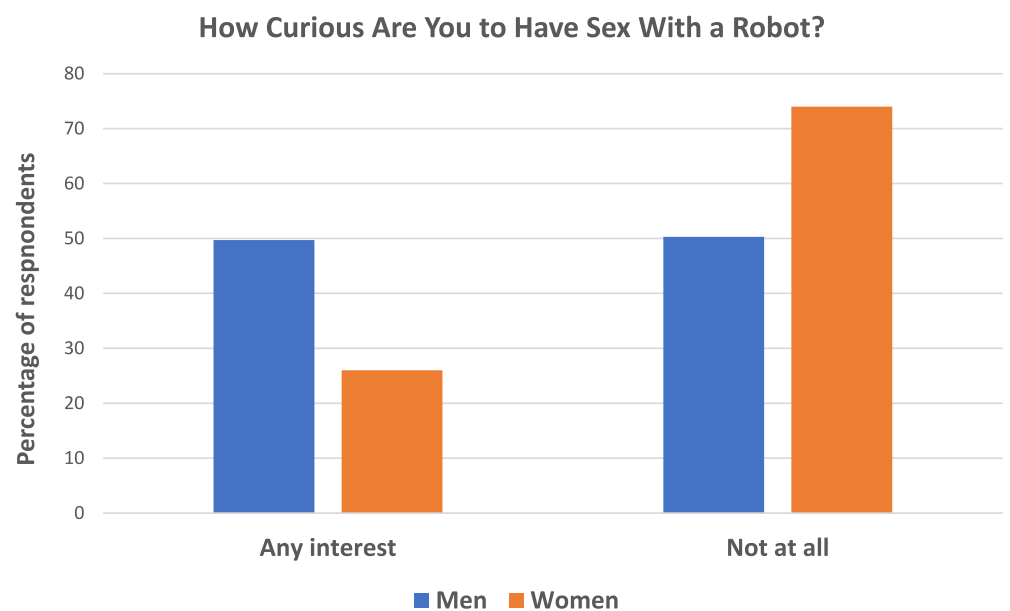

(a)

Do You Consider Sex With A Robot

To Be Cheating?

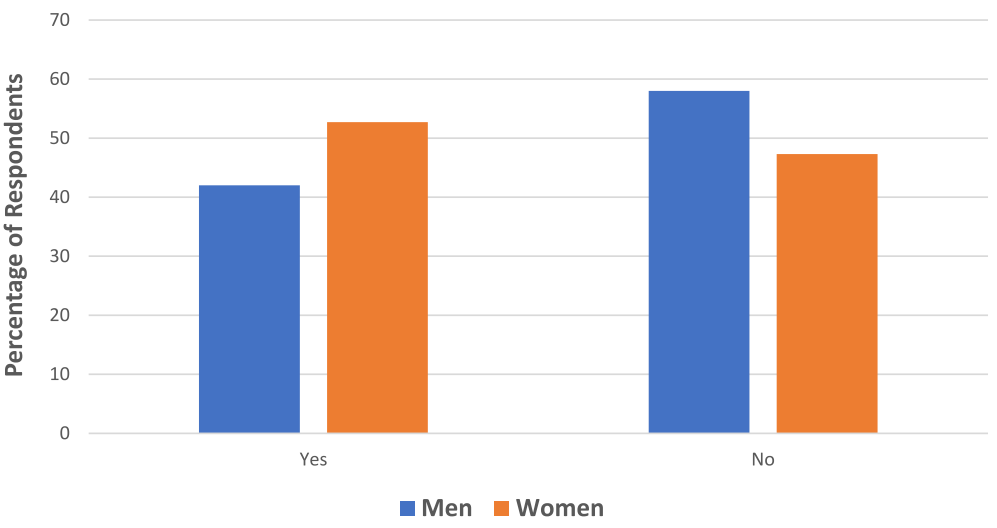

(b)

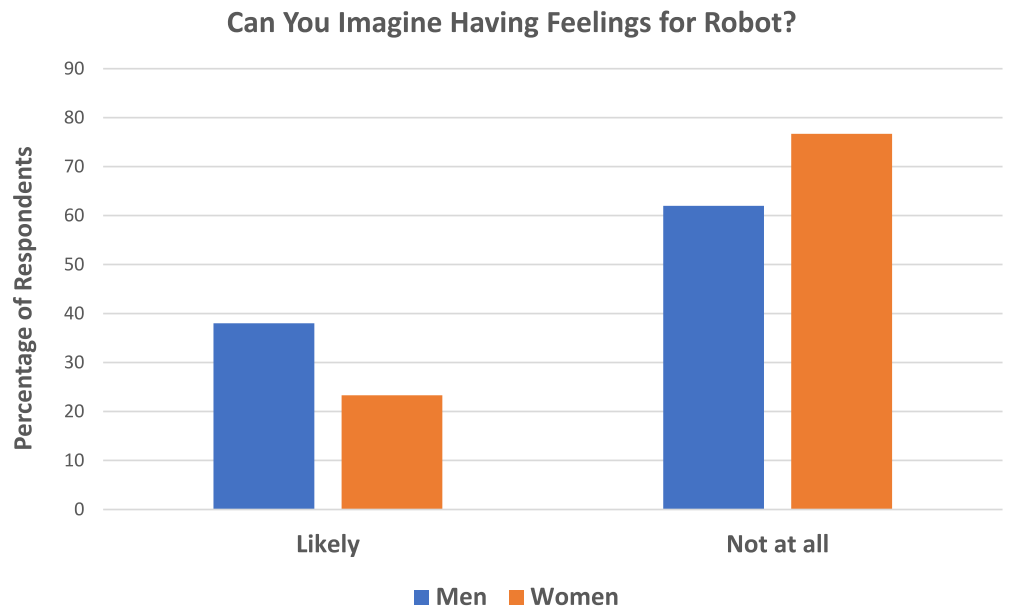

(c)

Fig. 1. Comparison of male and female responses to six questions regarding sex robots. Comparison of male and female responses all differed significantly with $P<0.001$ except for the question asking "Do you consider sex with a robot to be a form of cheating," for which $P=0.05$. 


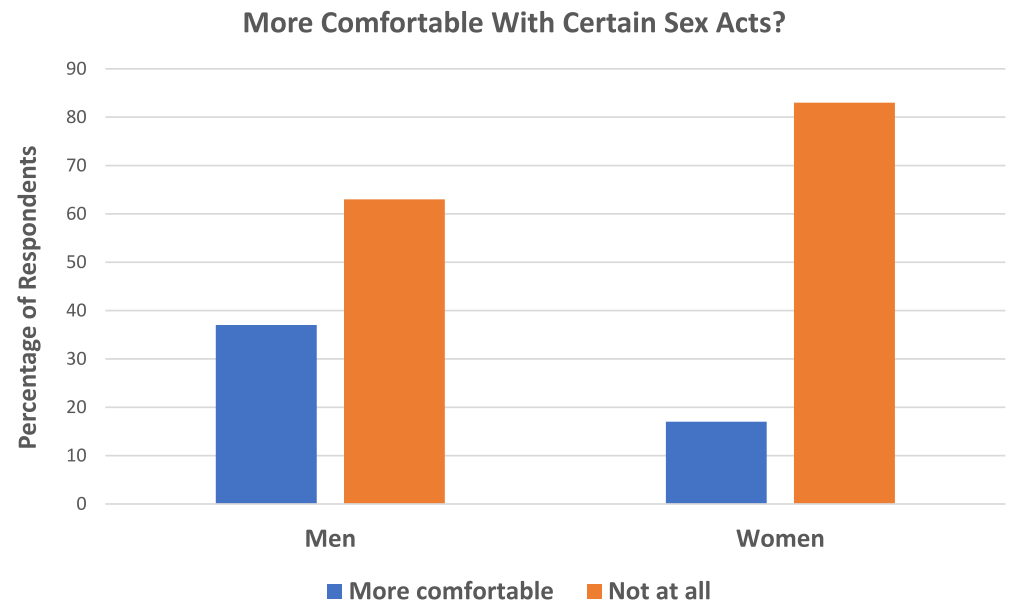

(d)

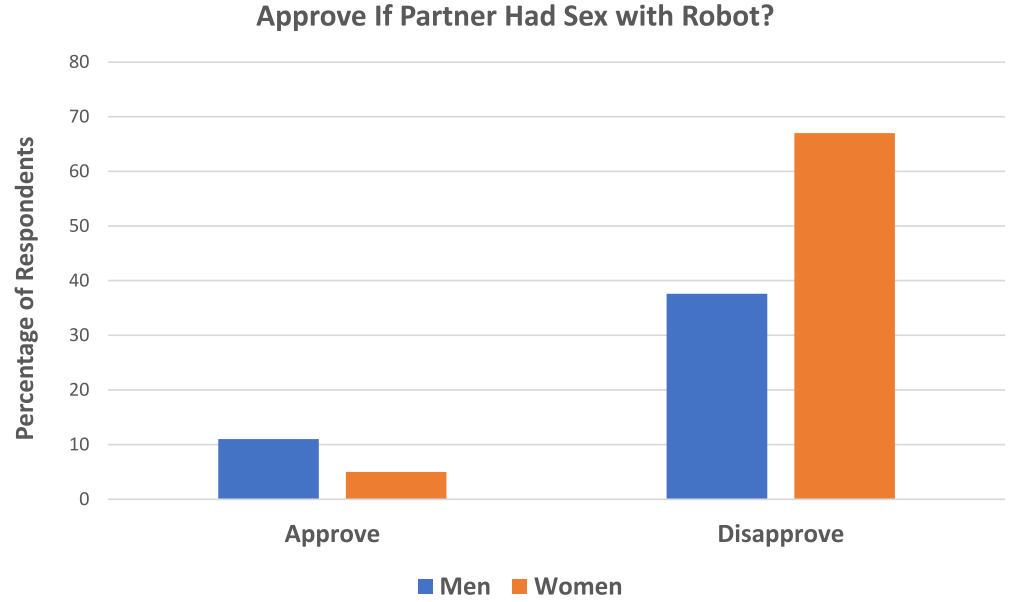

(e)

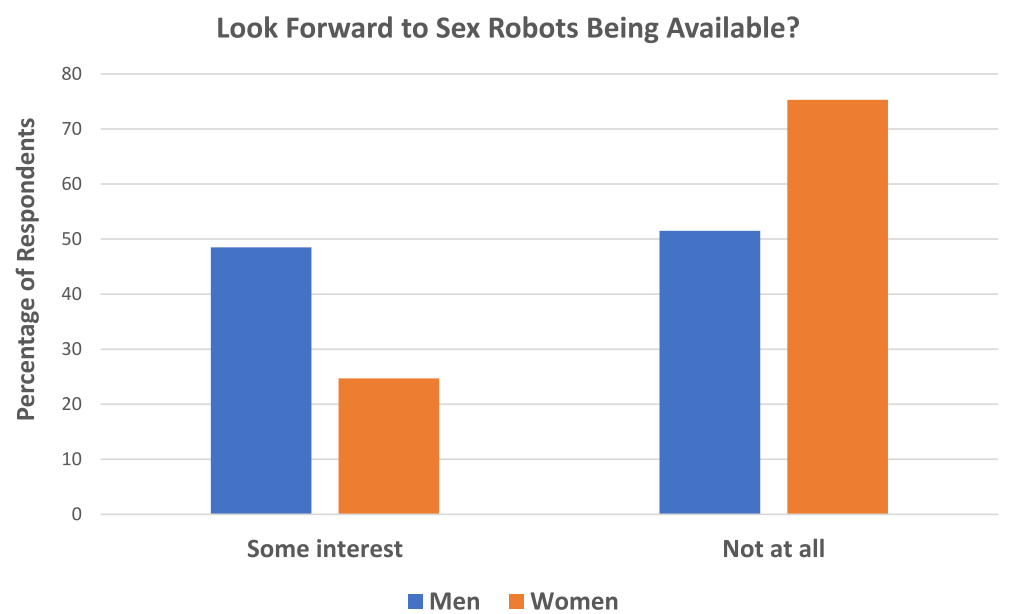

(f)

Fig. 1. (Continued.) 


\subsubsection{Influence of age}

Women showed no significant differences in responses based on age. The results for men are presented in Table 5. We chose to compare younger men ages 18-34 to men ages 55 and older. Differences between younger and older men were relatively small except for curiosity about having sex with a robot which was endorsed by $67 \%$ of younger men and $41 \%$ of older men $(p=0.02)$.

Table 5

Survey results from men stratified by age

\begin{tabular}{|c|c|c|c|c|c|}
\hline \multirow{2}{*}{$\begin{array}{l}\text { Questions } \\
\text { How curious are you to have sex with a robot? }\end{array}$} & \multicolumn{2}{|c|}{ Men age $18-34$} & \multicolumn{2}{|c|}{ Men age 55 and older } & \multirow[t]{2}{*}{ p-value } \\
\hline & Not at all & Any interest & Not at all & Any interest & \\
\hline & $33.3 \%$ & $30.9 \%$ & $59 \%$ & $41 \%$ & 0.02 \\
\hline \multirow[t]{2}{*}{ Do you consider sex with a robot to be a form of cheating? } & No & Yes & No & Yes & \\
\hline & $53.6 \%$ & $46.3 \%$ & $59 \%$ & $41 \%$ & NS \\
\hline \multirow{2}{*}{$\begin{array}{l}\text { Can you imagine having feelings for a robot, if that robot acts } \\
\text { loving towards you and appears to like being around you? }\end{array}$} & Not at all & Likely & Not & Likely & \\
\hline & $40.5 \%$ & $33.3 \%$ & 64 & & NS \\
\hline \multirow{2}{*}{$\begin{array}{l}\text { Could you be more comfortable doing certain sex acts with a } \\
\text { robot than with your partner? }\end{array}$} & Not & More & Not & More & \\
\hline & $30.9 \%$ & $42.9 \%$ & 46. & $33.3 \%$ & NS \\
\hline \multirow{2}{*}{$\begin{array}{l}\text { If you found out that your partner had sex with a robot, how } \\
\text { would you feel? }\end{array}$} & Disapprove & Approved & Disapprove & Approved & \\
\hline & $37.9 \%$ & $24.4 \%$ & $38.5 \%$ & $20.5 \%$ & NS \\
\hline \multirow{2}{*}{$\begin{array}{l}\text { Do you look forward to a time when sex with robots is easily } \\
\text { available? }\end{array}$} & Not at all & Some interest & Not at all & Some interest & \\
\hline & $66.7 \%$ & $33.3 \%$ & 64. & & NS \\
\hline
\end{tabular}

\subsubsection{Impact of relationship status}

Women showed no significant differences based on relationship status. For men, several questions regarding sex with robots differed between single men and those in a long-term committed relationship. Curiosity regarding sex with a robot was endorsed by $70 \%$ of single men and $46 \%$ of married men ( $p=0.01$ ), of which $36 \%$ and $14 \%$ respectively responded "a lot". Similarly, 39\% of single men expressed the possibility of being able to experience feelings for a robot, compared with $19 \%$ with married men $(p=0.02)$. When asked if they were looking forward to a time when sex with robots was easily available, $73 \%$ of single men and $43 \%$ of married men responded affirmatively, of which $36 \%$ and $15 \%$ responded "a lot," respectively $(p=0.002)$.

\subsubsection{Emotional connectedness}

We investigated whether responses differed based on degree of emotional connectedness for those currently in a relationship. Again, we found no differences for women. Among men currently in a relationship, overall endorsement of curiously about having sex with a robot was similar with $50 \%$ of men who felt connected and 55\% of men who felt unconnected ( $p=\mathrm{NS}$ ), of which $26 \%$ endorsed this enthusiastically for those not connected compared with $17 \%$ for those who felt connected. The belief that sex with robots is a form of cheating was endorsed by $51 \%$ of men who felt connected to their partner, and only $35 \%$ of men who did not feel connected ( $p=0.07$, NS).

\section{DISCUSSION}

For most people, sex is a critical aspect of an intimate relationship. In a world evidencing increasing levels of depression (Liu et al., 2020), stress (Torales et al., 2020; Liu et al., 2017), social isolation 
(Abrams et al., 2020; Hidaka, 2012), and the significant sexual challenges precipitated by COVID19 (Ibarra et al., 2020), a committed sex partner offers a powerful elixir for life's challenges. Any dynamics that impact human intimate relationships are thus worth discussion and attention.

Sex robots are an inevitable outgrowth of the massive technological expansion enjoyed by modern humans. It is likely that infants born today will know a world where sex robots are available and accessible. Such a profound shift in sexual technology will herald both advantages and disadvantages for human intimate relationships. This survey was conducted to explore gender differences in attitudes about sex robots.

Previous researchers explored the effect of gender and age on attitudes about sex robots (Scheutz and Arnold, 2016) as well as men's relationship status and sexual fulfillment on their intention to buy a sex robot (Szczuka \& Kramer, 2017a; 2017b). The current study extends previous knowledge with an initial attempt to explore some of the issues that are likely to surface in intimate relationships once sex robots become available. For example, one of the most common issues that bring couples to therapy is infidelity. Thus, a key question in the current survey is whether sex with a robot would be considered cheating. Our study showed that $42 \%$ of men and $52.7 \%$ of women responded affirmatively, making it one of the most relevant items in this survey from the standpoint of practitioners in sex therapy and sexual medicine. Similarly, the question assessing willingness to engage in certain sex acts with a robot rather than a human is an initial attempt to explore the possibility that people may find sex with a robot more fulfilling in some ways than sex with a human partner. To the best of our knowledge, ours was the first survey to examine the impact of all of these variables from this perspective. More research is needed to better comprehend these potential challenges.

Our results confirmed that men consistently report more positive reactions to sex with robots than women, as reported in prior research. Men expressed twice as much curiosity to have sex with a robot; they were twice as likely to imagine having romantic feelings for a robot; twice as likely to imagine engaging in certain sex acts with a robot partner versus a human partner; and four times as likely to approve of their romantic partner having sex with a robot. In all, twice as many men look forward to a time when sex robots are available, with three times as many men than women reported looking forward to it "a lot." Indeed, on no question did women report more enthusiasm or optimism about the arrival of sex robots than did men, and women were largely disapproving of a partner having sex with a robot. Past research has suggested that people who fantasize more and engage in more risky sexual behavior may be more likely to have sex with a robot (Richards et al., 2017). This finding may help to explain the significant differences we found between males and females in their reactions to sex robots, as research has consistently demonstrated that males report having sexual fantasies more than females (Baumeister et al., 2001), as well as engage in more risky sexual behaviors (Cubbins and Tanfer, 2000). If replicated, future research may continue to explore the reasons why males and females consistently demonstrate such different opinions of sex robots and their perception of potential benefits of having sex with a robot.

Men who were more satisfied with their sex lives also expressed more interest in having sex with robots. This finding appears consistent with previous research suggesting that sexual fulfillment does not influence men's desire to purchase a sex robot (Szczuka \& Kramer, 2017a; 2017b). Perhaps the men in our sample who were more satisfied with their relationships were simply more adventurous, or more sexual, than men who expressed less satisfaction.

We found only one age effect which suggested that male millennials (men ages 18-34) were significantly more curious to have sex with a robot than men age 55 and older. This result is consistent with past research demonstrating minimal cohort effects on attitudes toward sex robots (Scheutz and Arnold, 2016). Future research can further explore and clarify potential cohort effects. 
While the phenomenon of sex robots was introduced to the general public by David Levy in his groundbreaking book, Love and Sex with Robots (2007), there remains a paucity of research exploring attitudes and opinions toward sex robots (Richards et al., 2017). Our survey results were robust and consistent with previous research (Scheutz and Arnold, 2016) and with our predicted differences in gender responses. In spite of the fact that some women will inevitably be attracted to and enjoy having sex with robots, and male sex robots are already being manufactured to meet this demand, our research continues to suggest that men will be the overwhelming consumers of sex robots. Indeed, historically through today, males and females demonstrate significant differences in many sexual behaviors (Archer, 2019). For example, in spite of demonstrated female interest, men remain the primary consumers of porn (Carroll et al., 2017) and prostitution (Hammond \& van Hooff, 2020). Men report higher libidos (McNulty et al., 2019), a greater number of sex partners (McBurney et al., 2005), desire more sexual frequency (Smith et al., 2011) and a wider variety of sex acts (Schmitt et al., 2001), masturbate (Herbenick et al., 2010) and fantasize more than women (Wu et al., 2016; Baumeister et al., 2001). Men also report lower sexual disgust responses (Prokop and Jancovicova, 2013), and a greater willingness to take sexual risks than females (Cubbins and Tanfer, 2000). Men display the majority of paraphiliac interests (Dawson et al., 2014). In erotic scenes, males more typically attend to the genitals of the participants while females are more apt to focus on broader personality and relationship characteristics of the individuals, as well as the scene and context of the situation (Morandini et al., 2019). Taken together, these findings may indicate that males will more robustly seek and enjoy sex with robots than females.

This conclusion begs the question, What will sex robots mean to the future of gender relations, and in particular, sexual relationships? Engaging one another in a dialogue about the increasing impact technology will have on human intimacy can only strengthen our efforts to mold its effect into a primarily positive one. Certainly, with the sudden and severe impact of COVID-19 on the potential safety of nearly all sexual activity, sex robots may soon offer a safe alternative to human sexual relationships.

Our results must be interpreted in light of the limitations inherent in this research. Most obviously, there are limitations inherent in data gathered via crowdsourcing techniques. Online survey research solicits self-selected participants who may not adequately generalize to the population as a whole. Uncontrolled risks and biases may include cognitive bias, misinterpretation of questions, and malicious responding. Second, a limitation of our questionnaire includes the fact that all of our questions about attitudes toward sex robots were skewed in the positive direction and thus may be particularly susceptible to response bias. Third, sexual orientation and alternative relationship types were not assessed and may impact opinions about sex robots. Fourth, this research is based on speculation about experiences that will happen decades into the future. Younger cohorts, more accustomed to technology interfacing with all aspects of their personal lives, may have significantly different perceptions of sex with robots than adults are expressing today. As such, these results may prove inaccurate. Fifth, limitations of a cross-sectional research design include the inability to draw causative conclusions from the data obtained. For example, a third unassessed variable could be responsible for the apparent gender differences we have found, such as level of libido. Indeed, past research has considered correlations between positive reactions toward sex robots and the tendency to fantasize and engage in risky behavior (Richards et al., 2017). Researchers have speculated that cognitive style, and in particular Asperger's Disorder, may explain men's receptivity to sex dolls (Ciambron et al., 2017). Potential similarities in attitudes toward sex robots and prostitutes have been identified (Koverola et al., 2020; Gonzalez-Gonzalez et al., 2019; Richardson, 2016). For example, both sex robots and prostitution promote the objectifying of sex partners and involve the exchange of money for sex. Perhaps people with more positive attitudes toward prostitution will feel similarly toward sex robots. Further research 
will be necessary to more fully expand on and clarify these questions. Sixth, our questionnaire was created for the purpose of this study only, and has not been scientifically validated. Finally, the construct of sex robots was not defined for our research subjects. As such, it may be that individuals interpreted their responses based on a personal meaning of the term, rendering the compilation of our data less meaningful.

\section{CONCLUSION}

Today's widespread technological expansion impacts perhaps every aspect of human life. Sex robots are an inevitable consequence of this progress. The impact sex robots will have on human intimacy remains controversial and deserves our attention, particularly as human gender relations are already impacted by socio-cultural evolution and advancement. Our research replicates and expands on past findings that males have significantly more positive opinions and attitudes about sex robots than females. Indeed, on no question did women report more enthusiasm or optimism about the arrival of sex robots than did men. It is our expectation that dialogue about these gender differences can assist psychologists, sex therapists, anthropologists, roboticists and couples in navigating technological advancements as they increasingly impact human intimacy. Further research can only facilitate our challenge of utilizing sex robots to mostly enhance, rather than detract, from human intimacy and sexual satisfaction.

\section{REFERENCES}

Abrams, M., Williams, R. II., Tikkanen, R., Shah, T. \& Pantell, M. (2020). Solutions from Around the World: Tackling Loneliness and Social Isolation During COVID-19. To the Point (blog), Commonwealth Fund. doi:10.26099/h470-sy53.

Archer, J. (2019). The reality and evolutionary significance of human psychological sex differences. Biological Review, 94, 1381-1415.

Baum, S., Barrett, A. \& Yampolskiy, R. (2017). Modeling and interpreting expert disagreement about artificial intelligence. Informatica, 41, 419-427.

Baum, S., Goertzel, B. \& Goertzel, T. (2011). How long until human-level AI? Results from an expert assessment. Technological Forecasting and Social Change, 78, 185-195. doi:10.1016/j.techfore.2010. 09.006.

Baumeister, R., Catanese, K. \& Vohs, K. (2001). Is there a gender difference in strength of sex drive? Theoretical views, conceptual distinctions, and a review of relevant evidence. Personality and Social Psychology Review, 5, 242-273. doi:10.1207/S15327957PSPR0503_5.

Bergen, J. (2020). Love(rs) in the making: Moral subjectivity in the face of sexbots. Journal of Behavioral Robotics, 11, 284-300. doi:10.1515/pjbr-2020-0016.

Brandon, M. \& Morgentaler, A. (2016). Male and female sexual dysfunction in a rapidly changing cultural environment: Addressing gender equality vs equivalence in the bedroom. Sexual Medicine Reviews, 4, 96-102. doi:10.1016/j.sxmr.2015.12.002.

Burghardt, J., Beutel, M., Hasenburg, A., Schmutzer, G. \& Brahler (2020). Declining sexual activity and desire in women: Findings from representative German surveys 2005 and 2016. Archives of Sexual Behavior, 49, 919-925. 
Carroll, J., Busby, D., Willoughby, B. \& Brown, C. (2017). The porn gap: Differences in men's and women's pornography patterns in couple relationships. Journal of Couple \& Relationship Therapy, 16(2), 146-163. doi:10.1080/15332691.2016.1238796.

Ciambrone, D., Phua, V. \& Avery, E. (2017). Gendered synthetic love: Real dolls and the construction of intimacy. International Review of Modern Sociology, 43, 59-78.

Cubbins, L. \& Tanfer, K. (2000). The influence of gender on sex: A study of men's and women's self-reported high-risk sex behavior. Archives of Sexual Behavior, 29, 229-257. doi:10.1023/A: 1001963413640 .

Danaher, J. \& McArthur, N. (Eds.) (2017). Robot Sex: Social and Ethical Implications. Cambridge MA: MIT Press.

Dawson, S., Bannerman, B. \& Lalumiere, M. (2014). Paraphilic interests: An examination of sex differences in a non-clinical sample. Sexual Abuse, 28, 20-45. doi:10.1177/1079063214525645.

De Vries, G. \& Forger, N. (2015). Sex differences in the brain: A whole body perspective. Biology of Sex Differences, 6, 15. doi:10.1186/s13293-015-0032-z.

Doring, N. \& Poschl, S. (2018). Sex toys, sex dolls, sex robots: Our under researched bed-fellows. Sexologies, 27, 133-138. doi:10.1016/j.sexol.2018.05.003.

Edirisinghe, C. \& Cheok, A.D. (2017). Robots and intimacies: A preliminary study of perceptions and intimacies with robots. In A.D. Cheok, K. Devlin and D. Levy (Eds.), Love and Sex with Robots, Second International Conference, LSR 2016, London, UK December 19-20, 2016, (pp. 137-147). London: Springer.

Edirisinghe, C., Cheok, A.D. \& Khougali, N. (2018). Perceptions and responsiveness to intimacy with robots: A user evaluation. In A.D. Cheok and D. Levy (Eds.), Love and Sex with Robots, Third International Conference, LSR 2017, London, UK, December 19-20, 2017, (pp. 138-157). Switzerland: Springer.

Geher, G. \& Gambacorta, D. (2010). Evolution is not relevant to sex differences in humans because I want it that way! Evidence for the politicization of human evolutionary psychology. EvoS Journal: The Journal of Evolutionary Studies Consortium, 2, 32-47.

Goertzel, B. (2015). Superintelligence: Fears, promises, and potential. Journal of Evolution and Technology., 24, 55-87.

Gonzales-Gonzales, C., Gil-Iranzo, R. \& Paderewsky, P. (2019). Sex with robots: Analyzing the gender and ethics approaches in design. In Interaccion '19: Proceedings of the XX International Conference on Human Computer Interaction. doi:10.1145/3335595.3335609.

Hammond, N. \& van Hooff, J. (2020). "This is me, this is what I am, I am a man": The masculinities of men who pay for sex with women. The Journal of Sex Research, 57(5), 650-663. doi:10.1080/ 00224499.2019 .1644485 .

Herbenick, D., Reece, M., Schick, V., Sanders, S., Dodge, B. \& Fortenberry, J. (2010). Sexual behavior in the United States: Results from a national probability sample of men and women age 14-94. Journal of Sexual Medicine, 7, 255-265. doi:10.1111/j.1743-6109.2010.02012.x.

Hidaka, B. (2012). Depression as a disease of modernity: Explanations for increasing prevalence. Journal of Affective Disorders, 140(3), 205-214. doi:10.1016/j.jad.2011.12.036. 
Ibarra, F., Mehrad, M., Mauro, M., Godoy, M., Gruz, E., Nilforoushzadeh, M. \& Russo, G. (2020). Impact of the COVID-19 pandemic on the sexual behavior of the population. The vision of the east and the west. International Brazilian Journal of Urology, 46, 1677-6119.

Koverola, M., Dronsinou, M., Palomaki, J., Halonen, J., Kunnari, A., Repo, M., Lehtonen, N. \& Laakasuo, M. (2020). Moral psychology of sex robots: An experimental study - how pathogen disgust is associated with interhuman sex but not interandroid sex. Journal of Behavioral Robotics, 11, 233-249. doi:10.1515/pjbr-2020-0012.

Kunst, J., Bailey, A., Prendergast, C. \& Gundersen, A. (2019). Sexism, rape myths and feminist identification explain gender differences in attitudes toward the \#metoo social media campaign in two countries. Media Psychology, 22, 818-843. doi:10.1080/15213269.2018.1532300.

Levy, D. (2007). Love \& Sex with Robots. New York: HarperCollins.

Liberati, N. (2020). Making out with the world and valuing relationships with humans. Journal of Behavioral Robotics, 11, 140-146. doi:10.1515/pjbr-2020-0010.

Liu, M.-Y., Li, N., Li, W. \& Khan, H. (2017). Association between psychosocial stress and hypertension: A systematic review and meta-analysis. Neurological Research, 39, 573-580. doi:10.1080/ 01616412.2017.1317904.

Liu, Q., He, H., Yang, J., Feng, X., Zhao, F. \& Luy, J. (2020). Changes in the global burden of depression from 1990 to 2017: Findings from the Global Burden of Disease study. Journal of Psychiatric Research, 126, 134-140. doi:10.1016/j.jpsychires.2019.08.002.

McBurney, D., Zapp, D. \& Streeter, S. (2005). Preferred number of sex partners: Tails of distributions and tales of mating systems. Evolution and Human Behavior, 26, 271-278. doi:10.1016/j. evolhumbehav.2004.09.005.

McNulty, J., Maxwell, J., Maltzer, A. \& Baumeister, R. (2019). Sex-differentiated changes in sexual desire predict marital dissatisfaction. Archives of Sexual Behavior, 48, 2473-2481. doi:10.1007/ s10508-019-01471-6.

Morandini, J., Veldre, A., Holcombe, A., Hsuk, K., Lykins, A., Baily, J. \& Dar-Nimrod, I. (2019). Visual attention to sexual stimuli in mostly heterosexuals. Archives of Sexual Behavior, 48(5), 1371-1385. doi:10.1007/s10508-019-1419-4.

Muller, V. \& Bostrom, N. (2016). Future progress in artificial intelligence: A survey of expert opinion. In V.C. Muller (Ed.), Fundamental Issues of Artificial Intelligence, Switzerland: Springer. doi:10. 1007/978-3-319-26485-1.

Peterson, J. \& Hyde, J. (2010). A meta-analytic review of research on gender differences in sexuality, 1993-2007. Psychological Bulletin, 136, 21-38. doi:10.1037/a0017504.

Prokop, P. \& Jancovicova, M. (2013). Disgust sensitivity and gender differences: An initial test of the parental investment hypothesis. Problems of psychology in the $21^{\text {st }}$. Century, 7, 40-48.

Richards, R., Coss, C. \& Quinn, J. (2017). Exploration of relationship factors and the likelihood of a sexual robotic experience. In A.D. Cheok, K. Devlin and D. Levy (Eds.), Love and Sex with Robots, Second International Conference, LSR 2016, London, UK, December 19-20, 2016, (pp. 97-103). London: Springer.

Richardson, K. (2016). The asymmetrical "relationship": Parallels between prostitution and the development of sex robots. ACM SIGCAS Computers and Society, 45(3), 290-293. doi:10.1145/2874239. 2874281. 
Richardson, K. (2019). The human relationship in the ethics of robotics: A call to Martin Buber's I and Thou. AI \& Society, 34(1), 75-82. doi:10.1007/s00146-017-0699-2.

Scheutz, M. \& Arnold, T. (2016). Are we ready for sex robots? In Proceedings of the $11^{\text {th }}$ ACM/IEEE International Conference on Human Robot Interaction (pp. 351-358).

Scheutz, M. \& Arnold, T. (2018). Intimacy, bonding, and sex robots: Examining empirical results and exploring ethical ramifications. In J. Danaher and N. McArthur (Eds.), Robot Sex: Social and Ethical Implications (pp. 247-260). Cambridge, MA: The MIT Press.

Schmitt, D., Shackelford, T., Duntley, J., Tooke, W. \& Buss, D. (2001). The desire for sexual variety as a key to understanding basic human mating strategies. Personal Relationships, 8, 425-455. doi:10. 1111/j.1475-6811.2001.tb00049.x.

Smith, A., Lyons, A., Ferris, J., Richters, J., Pitts, M., Shelly, J. \& Simpson, J. (2011). Sexual and relationship satisfaction among heterosexual men and women: The importance of desired frequency of sex. Journal of Sex and Marital Therapy, 37, 104-115. doi:10.1080/0092623X.2011.560531.

Sotala, K. \& Yampolskiy, R. (2015). Responses to catastrophic AGI risk: A survey. Physica Scripta, 90(1), 018001. doi:10.1088/0031-8949/90/1/018001.

Szczuka, J. \& Kramer, N. (2017a). Influences on the intention to buy a sex robot: An empirical study on influences of personality traits and personal characteristics on the intention to buy a sex robot. In A.D. Cheok, K. Devlin and D. Levy (Eds.), Love and Sex with Robots, Second International Conference, LSR 2016, London, UK, December 19-20, 2016, (pp. 72-83). London: Springer.

Szczuka, J. \& Kramer, N. (2017b). Not only the lonely: How men explicitly and implicitly evaluate the attractiveness of sex robots in comparison to the attractiveness of women, and personal characteristics influencing this evaluation. Multimodal Technologies and Interaction, 1, 3. doi:10.3390/mti1010003.

Szczuka, J. \& Kramer, N. (2018). Jealousy 4.0? An empirical study on jealousy-related discomfort of women evoked by other women and gynoid robots. Journal of Behavioral Robotics, 9, 323-336. doi:10.1515/pjbr-2018-0023.

Torales, J., O’Higgins, M., Castaldelli-Maia, J. \& Ventiglio, A. (2020). The outbreak of COVID-19 coronovirus and its impact on global mental health. International Journal of Social Psychiatry, 66, 317-320. doi:10.1177/0020764020915212.

Ueda, P., Mercer, C., Ghaznavi, C. \& Herbenick, D. (2020). Trends in frequency of sexual activity and number of sex partners among adults ages 18 to 44 years in the US, 2000-2018. JAMA Network Open, 3, e203833. doi:10.1001/jamanetworkopen.2020.3833.

Viik, T. (2020). Falling in love with robots: A phenomenological study of experiencing technological alterities. Journal of Behavioral Robotics, 11, 52-65. doi:10.1515/pjbr-2020-0005.

Wu, Y., Ku, L. \& Zaroff, C. (2016). Sexual arousal and sexual fantasy: The influence of gender, and the measurement of antecedents and emotional consequences in Macau and the United States. International Journal of Sexual Health, 28, 55-69. doi:10.1080/19317611.2015.1111281. 